\title{
Antifungal susceptibilities of Candida, Cryptococcus neoformans and Aspergillus fumigatus from the Asia and Western Pacific region: data from the SENTRY antifungal surveillance program (2010-2012)
}

\author{
Michael A Pfaller, Shawn A Messer, Ronald N Jones and Mariana Castanheira
}

The SENTRY Antifungal Surveillance Program monitors global susceptibility rates of newer and established antifungal agents. We report the in vitro activity of seven antifungal agents against 496 contemporary clinical isolates of yeasts and molds. The isolates were obtained from 20 laboratories in the Asia-Western Pacific (APAC) region during 2010 through 2012. Anidulafungin, caspofungin, micafungin, fluconazole, itraconazole, posaconazole and voriconazole were susceptibility tested using CLSI methods and species-specific interpretive criteria. Sequencing of $f k s$ hot spots was performed for echinocandin-resistant strains. Isolates included 13 species of Candida ( $n=460), 5$ species of non-Candida yeasts (21), 5 species of Aspergillus (11) and 4 other molds. Echinocandin resistance was uncommon among eight species of Candida and was only detected in three isolates of Candida glabrata, two from Australia harboring mutations in fks1 (F625S) and fks2 (S663P). Resistance to the azoles was much more common and was observed among all species with the exception of Candida dubliniensis. Fluconazole resistance rates observed with $C$. glabrata (6.8\%) was comparable to that seen with Candida parapsilosis (5.7\%) and Candida tropicalis (3.6\%). Cross resistance among the triazoles was seen with each of these three species. The mold-active azoles and the echinocandins were all active against isolates of Aspergillus fumigatus. Azole resistance was not detected among the isolates of Cryptococcus neoformans. Antifungal resistance is uncommon among isolates of fungi causing invasive fungal infections in the APAC region. As in other regions of the world, emerging resistance to the echinocandins among invasive isolates of $C$. glabrata bears close monitoring.

The Journal of Antibiotics (2015) 68, 556-561; doi:10.1038/ja.2015.29; published online 22 April 2015

\section{INTRODUCTION}

Surveillance programs devoted to tracking the occurrence of invasive fungal infections (IFI) have provided a wealth of information regarding emerging species and the frequency of antifungal resistance. ${ }^{1-9}$ The increasing incidence of IFIs in the Asia and Western Pacific (APAC) regions have resulted in both small- and large-scale surveillance efforts in Australia, ${ }^{10,11}$ India, ${ }^{12,13}$ Japan, ${ }^{14}$ Korea, ${ }^{15-18}$ Malaysia, ${ }^{19}$ Singapore, ${ }^{20}$ Taiwan $^{21-27}$ and several other areas. ${ }^{8,9}$ In contrast to data from North America and Europe, ${ }^{1,7}$ Candida glabrata and Candida krusei are much less prominent as causes of IFI than either Candida tropicalis or Candida parapsilosis in several areas of the APAC region. Furthermore, resistance to fluconazole is much more common in isolates of $C$. tropicalis from Asia (11-15\%) than in those from North America (2.7\%) or Europe (1.1\%). 7,22,27

One of the limitations of the existing surveillance data from the APAC region is that most reports have not used the new speciesspecific interpretive criteria for the azoles and echinocandins against Candida and Aspergillus. In addition, many of these reports are limited to a single institution and most fail to compare results across several different countries or cities. The SENTRY Antimicrobial Surveillance Program is a survey that has been active since 1997 and has reported the frequency of pathogen occurrence and the susceptibilities to various antifungal agents on a global scale. ${ }^{7,28}$ In the present study, we summarize the results of the APAC component of the SENTRY Program for the years 2010 through 2012, comparing the activities of three echinocandins and four triazoles tested against a collection of 496 isolates of Candida (460 isolates, 13 species), non-Candida yeasts (21 isolates, 3 species), Aspergillus (11 isolates, 5 species) and non-Aspergillus molds (4 isolates, 4 species). Data from institutions in China are summarized in a separate publication (Pfaller et al., ${ }^{29,30}$ ). We have used molecular methods to confirm the identification of the less common species of Candida, as well as those of the non-Candida yeasts and all of the filamentous fungi. Furthermore, we applied the newly revised clinical breakpoints for the echinocandins, fluconazole and voriconazole to determine the resistance profiles of various Candida species ${ }^{31}$ and the epidemiological cutoff values (ECVs) for these agents, as well as itraconazole and posaconazole, to detect emerging, resistance among less common species of Candida ${ }^{31}$ and 
among isolates of Aspergillus fumigatus ${ }^{32}$ and Cryptococcus neoformans. ${ }^{33}$

\section{MATERIALS AND METHODS}

Organisms

A total of 496 clinical isolates from patients with IFI were collected during 2010 through 2012 from 20 different laboratories in Australia (6 sites, 177 isolates), Hong Kong ( 1 site, 23 isolates), India ( 3 sites, 7 isolates), Korea (4 sites, 87 isolates), New Zealand (2 sites, 64 isolates), Singapore (1 site, 65 isolates), South Africa ( 1 site, 18 isolates), Taiwan ( 1 site, 3 isolates) and Thailand (1 site, 52 isolates) as part of the SENTRY Program (Table 1). In each case, collection was approved by the appropriate institutional review board. Each participating center recovered consecutive, non-duplicated isolates from patients with bloodstream infections, normally sterile body fluids, abscess, and tissue samples and respiratory tract infections (Aspergillus and other molds only). Isolates were identified at the participating institutions using methods routinely used at the submitting laboratory, including Vitek, MicroScan, API and Auxacolor, supplemented by classical methods for yeast and mold identification. ${ }^{34,35}$ Isolates were submitted to JMI Laboratories (North Liberty, IA, USA), where the identification was confirmed by morphological, biochemical and molecular methods (all non-Candida yeasts and all molds) as described previously. ${ }^{7,29}$

Among the 460 isolates of Candida, there were 197 isolates of C. albicans, 88 of C. glabrata, 88 of C. parapsilosis, 55 of C. tropicalis, 8 of Candida dubliniensis, 7 of Candida guilliermondii, 5 of C. krusei, 5 of Candida lusitaniae and 6 of miscellaneous Candida spp. (2 Candida fabianii, 1 Candida haemulonii, 1 Candida kefyr, 1 Candida metapsilosis, and 1 Candida orthopsilosis). The collection also included C. neoformans (16 isolates), Lodderomyces elongisporus (1 isolate) Rhodotorula mucilaginosa (1 isolate), Saccharomyces cerevisiae (1 isolate) and Trichosporon asahii (2 isolates). Molds included A. fumigatus (six isolates), A. clavatus (one isolate), Aspergillus foetidis (one isolate), Aspergillus niger species complex (two isolates), Aspergillus section Terrei (one isolate), and four other molds (one Lichtheimia ramosa, one Scedosporium aurantiacum, one Scedosporium prolificans and one Trichoderma longibrachiatum).

\section{Antifungal susceptibility testing}

All yeasts were tested for in vitro susceptibility to the echinocandins (anidulafungin, caspofungin and micafungin) and the triazoles (fluconazole, posaconazole and voriconazole) using $\mathrm{CLSI}^{36}$ broth microdilution methods. The Minimum inhibitory concentration (MIC) results for all agents were read following $24 \mathrm{~h}$ of incubation when the agents were tested against Candida spp., whereas MIC end points for the triazoles were read after $48 \mathrm{~h}$ when the drugs were tested against non-Candida yeasts. ${ }^{36}$ In all instances, the MIC values were determined visually as the lowest concentration of drug that caused significant growth diminution levels ( $\geqslant 50 \%$ inhibition relative to the growth control). ${ }^{36,37}$

In vitro susceptibility testing of Aspergillus spp. and other molds against the echinocandins and triazoles (itraconazole, posaconazole and voriconazole) was performed by broth microdilution as described in CLSI document M38-A2. ${ }^{38}$ The triazole MICs and echinocandin minimum effective concentrations were determined as defined in the CLSI reference method. ${ }^{38}$

We used the revised CLSI clinical breakpoint values and epidemiological cutoff values to differentiate susceptible/wild-type strains from resistant/nonwild-type strains of each species. ${ }^{31-33,36-40}$

Quality control was performed as recommended in CLSI documents M27$\mathrm{A} 3^{36}$ and $\mathrm{M} 38-\mathrm{A} 2^{38}$ using the strains C. krusei ATCC 6258 C. parapsilosis ATTC 22019, and A. fumigatus MYA-3626.

All isolates of Candida spp. that were resistant to one or more of the echinocandins were further characterized regarding the presence or absence of mutation in the hot spot regions of $f k s 1$ and $f k s 2$ (C. glabrata only) as described previously. ${ }^{41,42}$

Table 1 Geographic distribution of organisms collected during 2010 to 2012 from Asia-Western Pacific medical centers participating in the SENTRY Antifungal Surveillance Program

No. of isolates in each geographic region

\begin{tabular}{|c|c|c|c|c|c|c|c|c|c|c|}
\hline Organism/organism group & AUS & $H K$ & IND & $K O R$ & $N Z$ & $S N G$ & $S A$ & $T W N$ & $T L D$ & Total \\
\hline Total, yeasts & 177 & 23 & 7 & 87 & 64 & 65 & 18 & 3 & 52 & 496 \\
\hline All Candida spp. & 159 & 23 & 7 & 85 & 61 & 65 & 15 & 3 & 42 & 460 \\
\hline C. albicans & 69 & 11 & 3 & 39 & 28 & 25 & 6 & 3 & 13 & 197 \\
\hline C. glabrata & 38 & 4 & & 13 & 12 & 13 & 1 & & 7 & 88 \\
\hline C. parapsilosis & 30 & 5 & 2 & 13 & 14 & 7 & 8 & & 9 & 88 \\
\hline C. tropicalis & 4 & 2 & 2 & 16 & 1 & 17 & & & 13 & 55 \\
\hline C. dubliniensis & 5 & & & & 2 & 1 & & & & 8 \\
\hline C. guilliermondii & 6 & & & & 1 & & & & & 7 \\
\hline C. krusei & 3 & 1 & & & 1 & & & & & 5 \\
\hline C. Iusitaniae & 2 & & & 2 & 1 & & & & & 5 \\
\hline C. fabianii & & & & 2 & & & & & & 2 \\
\hline C. haemulonii & & & & & & 1 & & & & 1 \\
\hline C. kefyr & 1 & & & & & & & & & 1 \\
\hline C. metapsilosis & & & & & & 1 & & & & 1 \\
\hline C. orthopsilosis & 1 & & & & & & & & & 1 \\
\hline Cryptococcus neoformans & 5 & & & 1 & 1 & & 3 & & 6 & 16 \\
\hline Other yeasts ${ }^{a}$ & 2 & & & & 2 & & & & 1 & 5 \\
\hline \multicolumn{11}{|l|}{ Mold } \\
\hline All Aspergillus spp. & 8 & & & & & & & & 3 & 11 \\
\hline A. fumigates & 5 & & & & & & & & 1 & 6 \\
\hline Other Aspergillus spp. ${ }^{\mathrm{b}}$ & 3 & & & & & & & & 2 & 5 \\
\hline Other molds ${ }^{c}$ & 3 & & & 1 & & & & & & 4 \\
\hline
\end{tabular}

Abbreviations: AUS, Australia; HK, Hong Kong; IND, India; KOR, Korea; NZ, New Zealand; SNG, Singapore; SA, South Africa; TWN, Taiwan; TLD, Thailand.

aOther yeasts include Lodderomyces, elongisporus (one strain), Rhodotorula, mucilaginosa, (one strain), Saccharomyces cerevisiae,(one strain) and Trichosporon asahii (two strains).

aOther yeasts include Lodderomyces, elongisporus (one strain), Rhodotorula, mucilaginosa, (one strain), Saccharomyces cerevisiae,(one strain) and Trichosporon as
bOther Aspergillus spp. include A. clavatus (one strain), A. foetidus (one strain), A. niger species complex (two strains), and Aspergillus section Terrei (one strain).

'Other molds include Lichtheimia ramosa (one strain), Scedosporium aurantiacum (one strain), Scedosporium prolificans (ome strain) and Trichoderma longibrachiatum (one strain). 
Table 2 Frequency of antifungal resistance among clinical isolates of Candida spp., Cryptococcus neoformans and Aspergillus fumigatus from the Asia-Western Pacific Region in the 2010-2012 SENTRY Surveillance Program

\begin{tabular}{|c|c|c|c|c|c|c|}
\hline \multirow[b]{2}{*}{ Species (no. tested) } & \multirow[b]{2}{*}{ Antifungal agent } & \multicolumn{3}{|c|}{ MIC/MEC $\left(\mu g \mathrm{ml}^{-1}\right)$} & \multicolumn{2}{|c|}{$\%$ by category ${ }^{a, b}$} \\
\hline & & Range & $50 \%$ & $90 \%$ & $s$ & $R$ \\
\hline \multicolumn{7}{|l|}{ C. albicans (197) } \\
\hline & Anidulafungin & $\leqslant 0.008-0.25$ & 0.015 & 0.06 & 100.0 & 0.0 \\
\hline & Caspofungin & $\leqslant 0.008-0.12$ & 0.03 & 0.06 & 100.0 & 0.0 \\
\hline & Micafungin & $\leqslant 0.008-0.12$ & 0.015 & 0.03 & 100.0 & 0.0 \\
\hline & Fluconazole & $\leqslant 0.06->128$ & 0.12 & 0.25 & 99.5 & 0.5 \\
\hline & Posaconazole & $\leqslant 0.008->8$ & 0.03 & 0.06 & 93.4 & 6.6 \\
\hline & Voriconazole & $\leqslant 0.008->8$ & $\leqslant 0.008$ & 0.015 & 99.5 & 0.5 \\
\hline \multicolumn{7}{|l|}{ C. glabrata (88) } \\
\hline & Anidulafungin & $0.03-1$ & 0.06 & 0.12 & 94.3 & 3.4 \\
\hline & Caspofungin & $0.015-1$ & 0.03 & 0.12 & 94.3 & 1.1 \\
\hline & Micafungin & $\leqslant 0.008-0.5$ & 0.015 & 0.03 & 97.7 & 1.1 \\
\hline & Fluconazole & $1-128$ & 8 & 32 & $(93.2)$ & 6.8 \\
\hline & Posaconazole & $0.25->8$ & 1 & 2 & 97.7 & 2.3 \\
\hline & Voriconazole & $0.03-4$ & 0.25 & 0.5 & 90.9 & 9.1 \\
\hline \multicolumn{7}{|l|}{ C. parapsilosis (88) } \\
\hline & Anidulafungin & $0.25-4$ & 2 & 4 & 88.6 & 0.0 \\
\hline & Caspofungin & $0.12-2$ & 0.25 & 0.05 & 100.0 & 0.0 \\
\hline & Micafungin & $0.25-4$ & 1 & 2 & 98.9 & 0.0 \\
\hline & Fluconazole & $0.12->128$ & 0.5 & 4 & 87.5 & 5.7 \\
\hline & Posaconazole & $0.015-0.5$ & 0.06 & 0.25 & 98.9 & 1.1 \\
\hline & Voriconazole & $\leqslant 0.008-4$ & 0.015 & 0.06 & 94.3 & 1.1 \\
\hline \multicolumn{7}{|l|}{ C. tropicalis (55) } \\
\hline & Anidulafungin & $\leqslant 0.008-0.06$ & 0.015 & 0.03 & 100.0 & 0.0 \\
\hline & Caspofungin & $\leqslant 0.008-0.06$ & 0.03 & 0.06 & 100.0 & 0.0 \\
\hline & Micafungin & $\leqslant 0.008-0.06$ & 0.03 & 0.03 & 100.0 & 0.0 \\
\hline & Fluconazole & $0.12-64$ & 0.25 & 1 & 94.6 & 3.6 \\
\hline & Posaconazole & $\leqslant 0.008-0.25$ & 0.06 & 0.12 & 96.4 & 3.6 \\
\hline & Voriconazole & $\leqslant 0.008-2$ & 0.03 & 0.03 & 94.6 & 3.6 \\
\hline \multicolumn{7}{|l|}{ C. dubliniensis (8) } \\
\hline & Anidulafungin & $0.015-0.06$ & 0.03 & - & 100.0 & 0.0 \\
\hline & Caspofungin & $\leqslant 0.008-0.06$ & 0.03 & - & 100.0 & 0.0 \\
\hline & Micafungin & $\leqslant 0.008-0.03$ & 0.03 & - & 100.0 & 0.0 \\
\hline & Fluconazole & $\leqslant 0.06-0.25$ & 0.12 & - & 100.0 & 0.0 \\
\hline & Posaconazole & $0.015-0.06$ & 0.03 & - & 100.0 & 0.0 \\
\hline & Voriconazole & $\leqslant 0.008$ & $\leqslant 0.008$ & - & 100.0 & 0.0 \\
\hline \multicolumn{7}{|l|}{ C. guilliermondii (7) } \\
\hline & Anidulafungin & $0.25-2$ & 2 & - & 100.0 & 0.0 \\
\hline & Caspofungin & $0.06-0.5$ & 0.25 & - & 100.0 & 0.0 \\
\hline & Micafungin & $0.06-1$ & 0.5 & - & 100.0 & 0.0 \\
\hline & Fluconazole & $2-8$ & 2 & - & 100.0 & 0.0 \\
\hline & Posaconazole & $0.12-1$ & 0.25 & - & 85.7 & 14.3 \\
\hline & Voriconazole & $0.03-0.25$ & 0.06 & - & 85.7 & 14.3 \\
\hline \multicolumn{7}{|l|}{ C. krusei (5) } \\
\hline & Anidulafungin & $0.03-0.12$ & 0.06 & - & 100.0 & 0.0 \\
\hline & Caspofungin & $0.06-0.25$ & 0.06 & - & 100.0 & 0.0 \\
\hline & Micafungin & $0.06-0.12$ & 0.12 & - & 100.0 & 0.0 \\
\hline & Posaconazole & $0.25-1$ & 0.5 & - & 80.0 & 20.0 \\
\hline & Voriconazole & $0.12-0.5$ & 0.25 & - & 100.0 & 0.0 \\
\hline
\end{tabular}




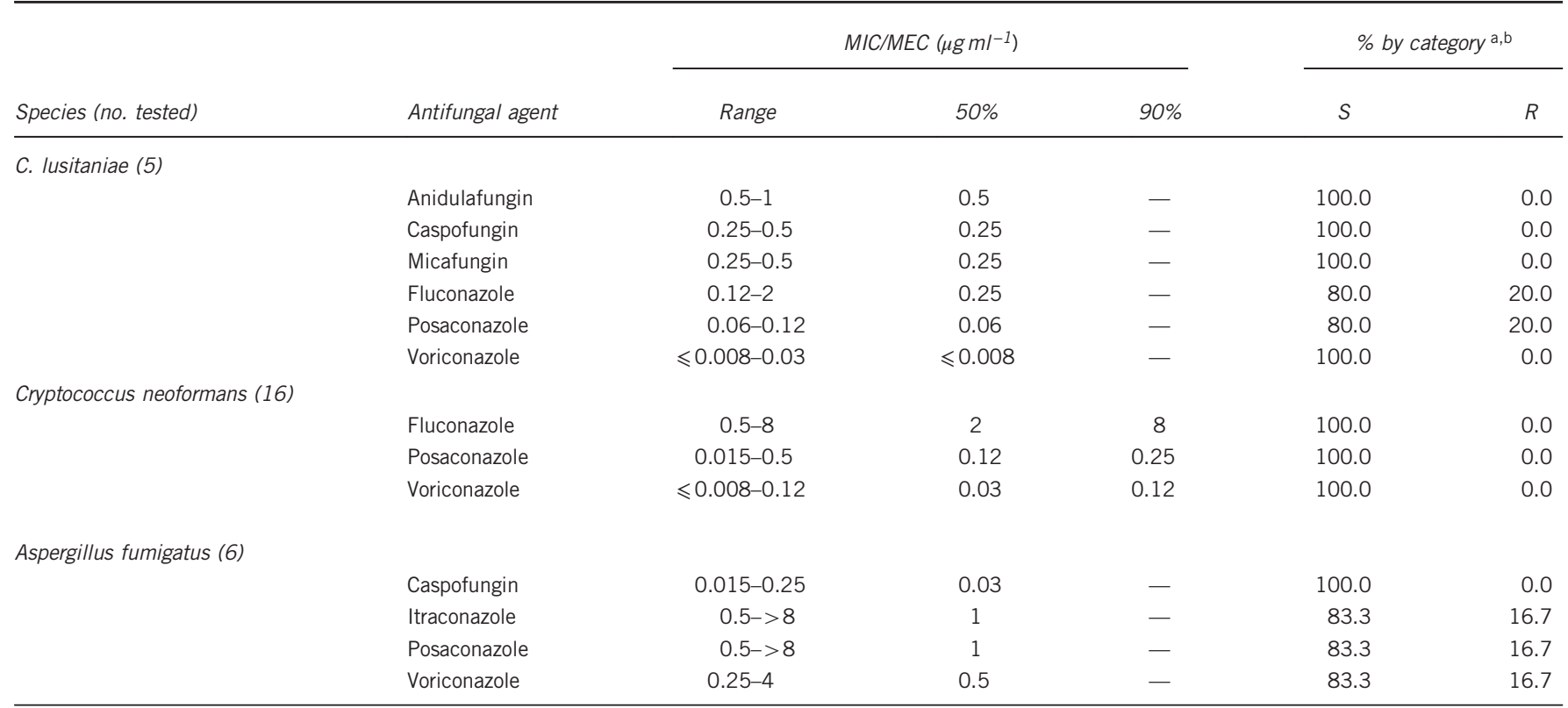

Abbreviations: MIC, minimum inhibitory concentration; MEC, minimum effective concentration; S, susceptible; R, resistant; 50 and $90 \%$, MIC encompassing 50 and $90 \%$ of isolates tested, respectively.

Posaconazole ECVs were used to identify WT and non-WT isolates of C. albicans (ECV, $\left.0.06 \mu \mathrm{g} \mathrm{ml}{ }^{-1}\right)$, C. glabrata (ECV, $0.12 \mu \mathrm{g} \mathrm{ml} \mathrm{l}^{-1}$ ), C. parapsilosis (ECV, $0.25 \mu \mathrm{g} \mathrm{ml} \mathrm{l}^{-1}$ ), C. tropicalis (ECV, $\left.0.12 \mu \mathrm{g} \mathrm{ml}^{-1}\right)$, and C. krusei (ECV, $\left.0.5 \mu \mathrm{g} \mathrm{ml}^{-1}\right)$. $^{31}$

The species-specific ECVs for all antifungal agents were used to classify isolates of C. dubliniensis, C. guilliermondii, C. lusitaniae, C. neoformans and A. fumigatus. ${ }^{31-33,43}$

asusceptibility and resistance are defined as MICs of $\leqslant 0.25 \mu \mathrm{g} \mathrm{ml}^{-1}$ and $>0.5 \mu \mathrm{g} \mathrm{ml} l^{-1}$, respectively, for anidulafungin, caspofungin and micafungin against $C$. albicans, $C$. tropicalis and $C$. krusei, MICs of $<0.12 \mu \mathrm{g} \mathrm{ml}^{-1}$ and $>0.25 \mu \mathrm{g} \mathrm{ml}^{-1}$, respectively, for anidulafungin and caspofungin and MICs of $<0.06 \mu \mathrm{g} \mathrm{ml}{ }^{-1}$ and $>0.12 \mu \mathrm{g} \mathrm{ml} l^{-1}$, respectively, for micafungin against C. glabrata; MICs of $<2 \mu \mathrm{g} \mathrm{ml} l^{-1}$ and $>4 \mu \mathrm{g} \mathrm{ml}^{-1}$, respectively, for anidulafungin, caspofungin and micafungin and C. parapsilosis and C. tropicalis, MICs of $\leqslant 32 \mu \mathrm{gl} \mathrm{ml}^{-1}$ (susceptible dose dependent; SDD) and $>32 \mu \mathrm{g} \mathrm{ml}^{-1}$, respectively, against C. glabrata; MICs of $\leqslant 0.12 \mu \mathrm{g} \mathrm{m}^{-1}$ and $>0.5 \mu \mathrm{g} \mathrm{ml}{ }^{-1}$, respectively, for voriconazole against $C$. albicans, C. parapsilosis, and C. tropicalis; and MICs of $\leqslant 0.5 \mu \mathrm{g} \mathrm{m}^{-1}$ and $>1 \mu \mathrm{gm} \mathrm{ml}^{-1}$, respectively, against C. krusei. ${ }^{31}$

$\mathrm{b} / \mathrm{n}$ lieu of clinical breakpoints for voriconazole against C. glabrata, the epidemiological cutoff value (ECV) of $0.5 \mu \mathrm{g} \mathrm{ml} \mathrm{I}^{-1}$ was used to identify wild-type (WT; MIC $<\mathrm{ECV}$ ) and non-WT (MIC $>$ ECV) isolates. ${ }^{31}$

\section{RESULTS AND DISCUSSION}

Table 1 shows species distribution by country/geographic region of the fungi implicated in the IFIs in the APAC region during 2010-2012. As expected, Candida spp. accounted for the vast majority of infections in all countries. Candida albicans was most common in Taiwan (100.0\%; only three isolates) and least common in Thailand (31.0\%), whereas C. glabrata was most common in Australia (23.9\%) and least common in India and Taiwan (0.0\%). C. parapsilosis accounted for $53.3 \%$ of Candida infections in South Africa and was the second most common species in Hong Kong, India and New Zealand. C. tropicalis was most common in Thailand (31.0\%) and was second in rank order in India, Korea and Singapore. Other miscellaneous species were largely contributed by sites in Australia and New Zealand, reflecting increased efforts at species-level identification in these countries. ${ }^{11}$ The prominence of both C. tropicalis and C. parapsilosis over C. glabrata has been noted previously in other surveys in the APAC region. ${ }^{12,14-18,20,21}$

The non-Candida yeasts consisted largely of $C$. neoformans (76.2\%), the majority of which were contributed by Australia and Thailand. Similarly, the vast majority of the molds were contributed by Australia and Thailand, most of which were Aspergillus spp.

The frequency of resistance to the azoles and the echinocandins for the eight most common species of Candida, C. neoformans and A. fumigatus are shown in Table 2. Resistance to the echinocandins was very uncommon among the eight species of Candida and was only detected in three isolates of C. glabrata, two of which were from Australia. Among the three echinocandin-resistant strains of C. glabrata, one was resistant to all three echinocandins (MIC $\geqslant 0.5$ $\mu \mathrm{g} \mathrm{ml}^{-1}$ ) and harbored a S663F mutation in $f k s 2$, one was resisitant to anidulafungin (MIC, $0.5 \mu \mathrm{g} \mathrm{ml}^{-1}$ ), intermediate to both caspofungin (MIC, $0.25 \mu \mathrm{g} \mathrm{ml}^{-1}$ ) and micafungin (MIC, $0.12 \mu \mathrm{g} \mathrm{ml}^{-1}$ ) and harbored a F625S mutation in $f k s 1$ and one was resistant to anidulafungin (MIC, $0.5 \mu \mathrm{g} \mathrm{ml}^{-1}$ ) but susceptible to both caspofungin (MIC, $\leqslant 0.12$ $\mu \mathrm{g} \mathrm{ml}^{-1}$ ) and micafungin (MIC, $\leqslant 0.06 \mu \mathrm{g} \mathrm{ml}^{-1}$ ) and did not possess a mutation in either $f k s 1$ or $f k s 2$. These results are similar to previous reports from the APAC region where echinocandin resistance has been very uncommon. ${ }^{14,15,17,22,24,26}$ Whereas the earlier studies of echinocandin resistance among Candida spp. from APAC may have underestimated the frequency of resistance due to the use of old (higher) clinical breakpoint values, by using the new (lower) species-specific clinical breakpoints and epidemiological cutoff values we can confirm the lack of echinocandin resistance among most species from this region. The detection of echinocandin resistance among isolates of $C$. glabrata, yet susceptibility to this class among other species, is consistent with previous observations from North America, Europe and Latin America.?

In contrast to the echinocandins, resistance to the azoles was observed in all species of Candida with the exception of $C$. dubliniensis (Table 2). Cross resistance among the three triazoles was detected in all species with the exception of C. dubliniensis, C. guilliermondii, C. krusei and C. lusitaniae. Notably, the level of fluconazole resistance observed with C. glabrata (6.8\%) was comparable to that seen with C. parapsilosis (5.7\%) and C. tropicalis (3.6\%). Most of the earlier studies of azole resistance in the APAC region are similar to that shown in Table 2; however, relatively high levels of fluconazole resistance have been reported among isolates of $C$. glabrata (11-12\%) and C. tropicalis (11.6-15\%) from Taiwan. ${ }^{22,23,26,27}$ 
Similar to that seen with the echinocandins, azole resistance among the Candida spp. from the APAC region was comparable to that observed among isolates from North America and Europe. ${ }^{7}$

Azole resistance was not detected among the isolates of $C$. neoformans and a single isolate of $A$. fumigatus from Australia was found to be non-wild type to itraconazole (MIC $>1 \mu \mathrm{g} \mathrm{ml}^{-1}$ ), posaconazole $\left(\mathrm{MIC}>0.5 \mu \mathrm{g} \mathrm{ml}^{-1}\right)$ and voriconazole $\left(\mathrm{MIC}>1 \mu \mathrm{g} \mathrm{ml}^{-1}\right)$.

In summary, we provide additional information to the literature regarding the frequency of various fungal pathogens causing IFI and the accompanying antifungal resistance profiles of APAC isolates of Candida, Cryptococcus and Aspergillus spp. We acknowledge that a limitation of the survey is the relatively small number of isolates of both molds and non-Candida yeasts. Resistance to the echinocandins was rare and detected in C. glabrata isolates from Australia. This is consistent with data from other regions where C. glabrata is often the only species of Candida with resistance to this class of agents. Although azole resistance was apparent in most species of Candida, it was not as high as that reported from other surveys, most notably from Taiwan. ${ }^{22,23,26}$ Likewise, resistance to the azole antifungals was not detected among $C$. neoformans isolates and was seen in only a single isolate of $A$. fumigatus. Whereas the rank order of Candida spp. for the entire collection is similar to that shown in other geographic surveys (C. albicans $>$ C. glabrata $=C$. parapsilosis $>C$. tropicalis $>$ C. krusei and so on), there were six different patterns of Candida species across the nine different countries, further demonstrating the importance of local epidemiological data. Antifungal resistance is relatively uncommon among isolates of fungi causing IFIs in the APAC region. As in other regions of the world emerging resistance to the echinocandins among invasive isolates of C. glabrata bears close monitoring.

\section{ACKNOWLEDGEMENTS}

We acknowledge the excellent technical assistance of $\mathrm{K}$ Hass in the preparation of the manuscript and the valuable contributions of the participants in the SENTRY Program in the APAC region. The antifungal global surveillance program, which served as the source of data for this study is, in part, supported by Astellas Pharma Global Development, Inc. and Pfizer Inc. The preparation of this manuscript was supported by an educational grant from Astellas Pharma Global Medical Affairs. JMI Laboratories, Inc. has received research and educational grants in 2011-2013 from Aires, American Proficiency Institute, Anacor, Astellas, AstraZeneca, Bayer, bioMerieux, Cempra, Cerexa, Contrafect, Cubist, Dipexium, Furiex, GlaxoSmithKline, Johnson \& Johnson ( $\mathrm{J}$ and $\mathrm{J}$ ), LegoChem Biosciences Inc., Meiji Seika Kaisha, Merck, Nabriva, Novartis, Pfizer, PPD Therapeutics, Premier Research Group, Rempex, Rib-X Pharmaceuticals, Seachaid, Shionogi, The Medicines Co., Theravance, and ThermoFisher Scientific. Some JMI employees are advisors/consultants for Astellas, Cubist, Pfizer, Cempra, Cerexa-Forest, J\&J, and Theravance. In regard to speakers bureaus and stock options, none to declare.

1 Arendrup, M. C. Epidemiology of invasive candidiasis. Curr. Opin. Crit. Care. 16, 445-452 (2010).

2 Azie, N. et al. The PATH (Prospective Antifungal Therapy) Alliance registry and invasive fungal infections: update 2012. Diagn. Microbiol. Infect. Dis. 73, 293-300 (2012).

3 Cleveland, A. A. et al. Changes in incidence and antifungal drug resistance in candidemia: results from population-based laboratory surveillance in Atlanta and Baltimore, 2008-2011. Clin. Infect. Dis. 55, 1352-1361 (2012).

4 Howard, S. J. \& Arendrup, M. C. Acquired antifungal drug resistance in Aspergillus fumigatus: epidemiology and detection. Med. Mycol. 49(Suppl 1), S90-S95 (2011).

5 Peman, J. et al. Epidemiology, species distribution and in vitro antifungal susceptibility of fungaemia in a Spanish multicentre prospective survey. J. Antimicrob. Chemother. 67, 1181-1187 (2012).

6 Pfaller, M. A. \& Diekema, D. J. Epidemiology of invasive candidiasis: a persistent public health problem. Clin. Microbiol. Rev. 20, 133-163 (2007).
7 Pfaller, M. A., Messer, S. A., Woosley, L. N., Jones, R. N. \& Castanheira, M. Echinocandin and triazole antifungal susceptibility profiles of opportunistic yeast and mould clinical isolates (2010-2011); application of new CLSI clinical breakpoints and epidemiological cutoff values to characterize geographic and temporal trends of antifungal resistance. J. Clin. Microbiol. 51, 2571-2581 (2013).

8 Slavin, M. A. \& Chakrabarti, A. Opportunistic fungal infections in the Asia-Pacific region. Med. Mycol. 50, 18-25 (2012).

9 Sun, P. L. et al. Laboratory-based surveillance of human fungal pathogens in Asia. Mycoses 55, 49 (2012).

10 Chen, S. et al. Active surveillance for candidemia, Australia. Emerg. Infect. Dis. 12, 1508-1516 (2006).

11 Chen, S. C. et al. Candidaemia with uncommon Candida species: predisposing factors, outcome, antifungal susceptibility, and implications for management. Clin. Microbiol. Infect. 15, 662-669 (2009).

12 Chakrabarti, A., Chander, J., Kasturi, P. \& Panigrahi, D. Candidaemia: a 10-year study in an Indian teaching hospital. Mycoses 35, 47-51 (1992).

13 Chakrabarti, A. et al. Epidemiological study of a large cluster of fungaemia cases due to Kodamaea ohmeri in an Indian tertiary care centre. Clin. Microbiol. Infect. 20, 083-089 (2014)

14 Takakura, S. et al. National surveillance of species distribution in blood isolates of Candida species in Japan and their susceptibility to six antifungal agents including voriconazole and micafungin. J. Antimicrob. Chemother. 53, 283-289 (2004).

15 Choi, H. W. et al. In vitro susceptibilities to caspofungin and micafungin of clinical isolates of Candida species. Korean J. Lab. Med. 26, 275-281 (2006).

16 Jang, M. J. et al. In vitro fluconazole and voriconazole susceptibilities of Candida bloodstream isolates in Korea: use of the CLSI and EUCAST epidemiological cutoff values. Ann. Lab. Med. 33, 167-173 (2013).

17 Jung, S. I. et al. Multicenter surveillance of species distribution and antifungal susceptibilities of Candida bloodstream isolates in South Korea. Med. Mycol. 48 669-674 (2010).

18 Lee, J. S. et al. Species distribution and susceptibility to azole antifungals of Candida bloodstream isolates from eight university hospitals in Korea. Yonsei Med. J. 48, 779-786 (2007)

19 Santhanam, J., Nazmiah, N. \& Aziz, M. N. Species distribution and antifungal susceptibility patterns of Candida species: Is low susceptibility to itraconazole a trend in Malaysia? Med. J. Malaysia 68, 343-347 (2013).

20 Tan, T. Y., Tan, A. L., Tee, N. W. \& Ng, L. S. A retrospective analysis of antifungal susceptibilities of Candida bloodstream isolates from Singapore hospitals. Ann. Acad. Med. Singapore 37, 835-840 (2008).

21 Chen, P. L. et al. Species distribution and antifungal susceptibility of blood Candida isolates at a tertiary hospital in southern Taiwan, 1999-2006. Mycoses 54, e17-e23 (2011).

$22 \mathrm{Hii}, \mathrm{I} . \mathrm{M}$. et al. Changing epidemiology of candidemia in a medical center in middle Taiwan. J. Microbiol. Immunol. Infect. (e-pub ahead of print 7 October 2013 doi:10.1016/j.jmii.2013.08.017).

23 Hsueh, P. R., Teng, L. J., Yang, P. C., Ho, S. W. \& Luh, K. T. Emergence of nosocomial candidemia at a teaching hospital in Taiwan from 1981 to 2000: increased suscept ibility of Candida species to fluconazole. Microb. Drug Resist. 8, 311-319 (2002).

24 Lai, C. C. et al. Association between incidence of candidaemia and consumption of antifungal agents at a medical centre in Taiwan. Int. J. Antimicrob. Agents 40, 349-353 (2012)

25 Hsueh, P. R. et al. Consensus statement on the management of invasive candidiasis in intensive care units in the Asia-Pacific Region. Int. J. Antimicrob. Agents 34, 205-209 (2009).

26 Ruan, S. Y., Lee, L. N., Jerng, J. S., Yu, C. J. \& Hsueh, P. R. Candida glabrata fungaemia in intensive care units. Clin. Microbiol. Infect. 14, 136-140 (2008).

27 Yang, Y. L., Ho, Y. A., Cheng, H. H., Ho, M. \& Lo, H. J. Susceptibilities of Candida species to amphotericin $\mathrm{B}$ and fluconazole: the emergence of fluconazole resistance in Candida tropicalis. Infect. Control Hosp. Epidemiol. 25, 60-64 (2004).

28 Pfaller, M. A., Castanheira, M., Messer, S. A., Moet, G. J. \& Jones, R. N. Echinocandin and triazole antifungal susceptibility profiles for Candida spp., Cryptococcus neoformans, and Aspergillus fumigatus: application of new CLSI clinical breakpoints and epidemiologic cutoff values to characterize resistance in the SENTRY Antimicrobial Surveillance Program (2009). Diagn. Microbiol. Infect. Dis. 69, 45-50 (2011).

29 Pfaller, M. A., Woosley, L. N., Messer, S. A., Jones, R. N. \& Castanheira, M. Significance of molecular identification and antifungal susceptibility of clinically significant yeasts and moulds in a global antifungal surveillance program. Mycopathologia 174, 259-271 (2012).

30 Pfaller, M. A., Castanheira, M., Messer, S. A., Jones, R. N. In vitro antifungal susceptibilities of isolates of Candida spp. and Aspergillus spp. from China to nine systemically active antifungal agents: data from the SENTRY antifungal surveillance program, 2010 through 2012. Mycoses. 58, 209-214 (2015).

31 Pfaller, M. A. \& Diekema, D. J. Progress in antifungal susceptibility testing of Candida spp. by use of Clinical and Laboratory Standards Institute broth microdilution methods, 2010 to 2012. J. Clin. Microbiol. 50, 2846-2856 (2012)

32 Espinel-Ingroff, A. et al. Wild-type MIC distributions and epidemiological cutoff values for the triazoles and six Aspergillus spp. for the CLSI broth microdilution method (M38A2 document). J. Clin. Microbiol. 48, 3251-3257 (2010).

33 Espinel-Ingroff, A. et al. Cryptococcus neoformans-Cryptococcus gattii species complex: an international study of wild-type susceptibility endpoint distributions and epidemiological cutoff values for fluconazole, itraconazole, posaconazole, and voriconazole. Antimicrob. Agents Chemother. 56, 5898-5906 (2012). 
34 Howell, S. A. \& Hazen, K. C. in: Candida, Cryptococcus, and other yeasts of medical importance (eds Versalovic J., Carroll K. C., Funke G., Jorgensen J. H., Landry M. L., Warnock D. W.) Manual of Clinical Microbiology 10th edn 1793-1821 (ASM Press, Washington, DC, USA, 2011)

35 Larone, D. H. Medically important fungi: a guide to identification 4th edn (ASM Press, Washington, DC, USA, 2002).

$36 \mathrm{CLSI}$. M27-A3. Reference Method for Broth Dilution Antifungal Susceptibility Testing of Yeasts 3rd edn (Clinical and Laboratory Standards Institute, Wayne, PA, USA, 2008).

37 CLSI. M27-S4. Reference Method for Broth Dilution Antifungal Susceptibility Testing of Yeasts 4th Informational Supplement (Clinical and Laboratory Standards Institute, Wayne, PA, USA, 2012).

38 CLSI. M38-A2. Reference Method for Broth Dilution Antifungal Susceptibility Testing of Filamentous Fungi 2nd edn (Clinical and Laboratory Standards Institute, Wayne, PA, USA, 2008).
39 Howard, S. J. et al. Frequency and evolution of azole resistance in Aspergillus fumigatus associated with treatment failure. Emerg. Infect. Dis. 15, 1068-1076 (2009).

40 Rodriguez-Tudela, J. L. et al. Epidemiological cutoffs and cross-resistance to azole drugs in Aspergillus fumigatus. Antimicrob. Agents Chemother. 52, 2468-2472 (2008).

41 Castanheira, M. et al. Low prevalence of $f k s 1$ hotspot 1 mutations in a worldwide collection of Candida spp. Antimicrob. Agents Chemother. 54, 2655-2659 (2010).

42 Castanheira, M. et al. Frequency of $f$ ks mutations among Candida glabrata isolates from a 10-year global collection of bloodstream infection isolates. Antimicrob. Agents Chemother. 58, 577-580 (2014).

43 Espinel-Ingroff, A. et al. Multilaboratory study of epidemiological cutoff values for detection of resistance in eight Candida species to fluconazole, posaconazole, and voriconazole. Antimicrob. Agents Chemother. 58, 2006-2012 (2014). 